\title{
An Approach for Examining the Impact of Food Group-Based Sources of Nutrients on Outcomes with Application to PUFAs and LDL in Youth with Type 1 Diabetes
}

\author{
Janet A. Tooze ${ }^{1, *(\mathbb{D})}$, Natalie S. The ${ }^{2}$, Jamie L. Crandell ${ }^{3}$, Sarah C. Couch ${ }^{4}$, \\ Elizabeth J. Mayer-Davis ${ }^{5}$, Corinna Koebnick ${ }^{6}$ and Angela D. Liese ${ }^{7}$ (D) \\ 1 Department of Biostatistics and Data Science, Wake Forest School of Medicine, Winston-Salem, \\ NC 27157, USA \\ 2 Department of Health Sciences, Furman University, Greenville, SC 29613, USA; Natalie.the@furman.edu \\ 3 School of Nursing and Department of Biostatistics, University of North Carolina at Chapel Hill, Chapel Hill, \\ NC 27599, USA; jbigelow@email.unc.edu \\ 4 Department of Rehabilitation, Exercise, and Nutrition Sciences, University of Cincinnati Medical Center, \\ Cincinnati, OH 45267-0394, USA; sarah.couch@uc.edu \\ 5 Departments of Nutrition and Medicine, University of North Carolina at Chapel Hill, Chapel Hill, NC 27599; \\ mayerdav@email.unc.edu \\ 6 Kaiser Permanente Southern California, Department of Research \& Evaluation, Pasadena, CA 91101, USA; \\ Corinna.Koebnick@kp.org \\ 7 Department of Epidemiology and Biostatistics, Arnold School of Public Health, University of South Carolina, \\ Columbia, SC 29208, USA; liese@mailbox.sc.edu \\ * Correspondence: jtooze@wakehealth.edu; Tel.: +1-336-716-3833
}

Received: 20 February 2020; Accepted: 25 March 2020; Published: 28 March 2020

\begin{abstract}
Traditionally, nutritional epidemiologists have utilized single nutrient or dietary pattern approaches to examine diet-health relationships. However, the former ignores that nutrients are consumed from foods within dietary patterns, and, conversely, dietary patterns may provide little information on mechanisms of action. Substitution provides a framework for estimating diet-health relationships while holding some nutrient intakes constant. We examined substitution effects of polyunsaturated fatty acids (PUFAs) in the SEARCH Nutrition Ancillary Study in the context of food group source. PUFAs were calculated from fatty acids 18:3, 20:5, and 22:6 (n-3), and 18:2 and 20:4 (n-6) from a food frequency questionnaire, quantified by food group. Models were adjusted for other fat intake, carbohydrates, protein, age, race, gender, and diabetes duration. Participants $(n=$ 1441) were 14 years old on average, $51 \%$ female, with type 1 diabetes for 3.6 years. Mean intake of PUFAs was $14.9 \mathrm{~g} /$ day, and the highest PUFA sources were nonsolid fats, nuts, grains, red/processed meats, sweets/desserts, and high-fat chicken. PUFAs from nuts were inversely associated with low-density lipoprotein cholesterol (LDL) $(p=0.03)$ and PUFAs from high-fat chicken were positively associated with LDL $(p<0.01)$. Substituting nuts for chicken was associated with $-7.4 \mathrm{mg} / \mathrm{dL}$ in LDL. These findings illustrate the importance of considering food group-based sources of nutrients when examining diet-health relationships.
\end{abstract}

Keywords: dietary patterns; LDL cholesterol; polyunsaturated fatty acids; food groups

\section{Introduction}

The common approach of describing the relationship between one nutrient and an outcome has identified specific mechanisms by which nutrients may affect health. For example, the intake of $n-6$ 
polyunsaturated fatty acids (PUFA) has been associated with lower levels of low-density lipoprotein (LDL) cholesterol and decreased risk of cardiovascular disease [1-4]. This approach, however, is a simplistic model of the impact of nutrition on health, as nutrients are typically obtained by consuming foods, which contain other nutrients and phytochemicals and are consumed within a dietary pattern. Thus, the traditional approach does not consider the specific food group-based source of a given nutrient. In addition to the nutrient-based approach, researchers have examined dietary patterns and their relationship to health. Although dietary patterns are appealing because they capture the complexity and multidimensionality of dietary intake, they provide little information in terms of potential mechanisms of action.

Substitution provides a valuable framework for both quantifying risk and exploring mechanisms of action while holding some nutrient intakes constant [5]. Using this approach, it is possible to consider nutrients and food groups simultaneously by modelling nutrients nested within food group. Only a few studies have examined the relationship between different food group sources of a nutrient and the impact on health [6,7] or examined the impact of nested food group components [8]. For example, de Oliveira Otto et al. found that a higher intake of saturated fat from dairy was associated with a significantly lower risk of cardiovascular disease (CVD), whereas a higher intake of saturated fat from meat was associated with greater risk of CVD. The authors concluded that substituting $2 \%$ of energy from meat with energy from dairy was associated with a $25 \%$ lower risk of cardiovascular disease [6]. Whereas their substitution model included energy and alcohol, it did not adjust for other fats, carbohydrates, or protein. Therefore, the specific source of the substitution on the comparison of the modelled nutrients could have been to a mix of carbohydrates, protein, and other fats, as well as one substituted saturated fatty acid for another.

The present study builds on the concept of substitution effects from a novel food group-based nutrients perspective. To illustrate our approach, we focused on the association between total PUFAs contained within food groups and LDL cholesterol using data from the SEARCH Nutrition Ancillary Study (SNAS), a study that investigated the relationship between dietary intake and complications of type 1 diabetes in youth, in a secondary data analysis. This particular application was chosen because previous research found that diets rich in PUFA, as opposed to those high in saturated fat, have been associated with lower LDL cholesterol in adults [1]. However, the relationship between PUFA intake and LDL cholesterol in youth with type 1 diabetes has been studied far less. In a small study of youth with type 1 diabetes in Australia $(n=79)$, PUFA was not associated with LDL cholesterol [9]. In contrast, among Japanese youth with type 1 diabetes, those with adolescent onset had lower levels of PUFA intake in comparison to those with childhood onset type 1 diabetes and had the highest level of LDL cholesterol [10]. We previously showed a significant inverse (favorable) association between plasma biomarkers of linoleic acid $(18: 2, n-6)$ and docosahexaenoic acid $(22: 6, n-3)$ and LDL cholesterol, and a significant positive (unfavorable) association between eicosapentaenoic acid (20:5, n-3) and LDL cholesterol in youth with type 1 diabetes [11]. One source of discrepancy between different estimates of the effects of PUFAs on LDL cholesterol may be the food sources of the PUFAs, i.e., different food sources contain different types of PUFAs, and examining them at the food group source level may elucidate relationships not found when examining them together. Furthermore, examining food-based sources of PUFAs may inform dietary guidance. Therefore, we sought to develop an approach to consider nutrients nested within food group sources. Specifically, we explored total PUFAs and $n-3$ and $n-6$ fatty acid subclasses separately using multivariable substitution models.

\section{Materials and Methods}

\subsection{Study Population and Design}

SEARCH for Diabetes in Youth is a population-based multi-center study of diabetes in youth less than 20 years of age with six recruitment centers (Cincinnati, Colorado, Hawaii, Seattle, South Carolina, and Southern California, including two American Indian reservation-based populations in Arizona and 
New Mexico directed by Colorado) [12]. Details of the study have been presented elsewhere [12,13]. Briefly, incident non-gestational cases of physician-diagnosed diabetes were identified from 2002 onward under Health Insurance Portability and Accountability Act waivers of consent. A cohort study was conducted among participants diagnosed from 2002-2005. The study was approved by the local institutional review boards at each site. The parent or guardian for those less than 18 years of age, and the participant if 18 years of age or older, provided written informed consent prior to the initiation of any study procedures or data collection, according to the requirements of the local institutional review board (IRB). The written assent of subjects who were less than 18 years of age was also governed by the requirements of the local IRB. Participants were asked to complete an initial survey, followed by an in-person visit with a physical examination, collection of blood and urine, and completion of interviewer-administered or self-administered questionnaires. This cross-sectional analysis was restricted to youth with type 1 diabetes (provider diagnosed and positive for at least one diabetes autoantibody, GAD65 or IA-2) whose diabetes was prevalent in 2001 or incident in 2002-2005 who were $\geq 10$ years of age at the time of their baseline study visit for at least three months.

\subsection{Development of Food Groups}

A modified Block Kids food frequency questionnaire (FFQ) with an expanded list of foods selected to reflect ethnic, cultural, and regional variation in the study population was used to assess dietary intake $[14,15]$. The FFQ consisted of 85 food lines for which the participant indicated if the item(s) was/were consumed in the past week ("yes/no"). If yes, participants indicated how many days and the average portion size. Portion size was queried for each line item in a manner relevant to the item either as a number (e.g., number of slices of bread) or as "very small," "small," "medium," or "large" relative to pictures of food in bowls or plates provided with the form. Additional foods were captured by an open-ended question at the end of the FFQ. The FFQ was primarily self-administered after staff instruction. The recipe and portion-size databases for this instrument were modified from the respective Diabetes Prevention Program databases, using the Nutrition Data System (NDS) for Research (database 3 version 4.05/33, 2002, Nutrition Coordinating Center, University of Minnesota, Minneapolis) and industry sources [15]. The nutrient composition of the recipes was computed using Nutrition Data System for Research (NDSR 2014) developed by the Nutrition Coordinating Center, University of Minnesota, Minneapolis, MN. The SEARCH FFQ has recently been validated and shown to have reasonable characteristics for the vast majority of food groups and nutrients needed for the purpose of this analysis [15].

To develop food groups, each line item was associated with a recipe, and each ingredient of the recipe was associated with a food group. Nutrients were calculated at the ingredient level, and then summed by food group to derive food group-based sources of nutrients. Total $n-3$ plus $n-6$ PUFAs were calculated from the sum of 18:3, 20:5, and 22:6 (n-3), and 18:2 and 20:4 $(n-6)$ as derived from the FFQ and were quantified by food group (Table 1). PUFA nutrient values were calculated for each ingredient used, but the ingredients may have been cooked or processed in some way. For example, the legume group included the ingredient of "refried beans," which have added fats that contain PUFAs in addition to beans (Table 1). After quantifying PUFAs from ingredients by food groups, food groups that provided less than $10.5 \mathrm{~kJ}$ ( $2.5 \mathrm{kcal}) /$ day from $n-3$ and $n-6$ PUFAs were collapsed into an "other" category used for modelling (sports bars, meal replacements, fruit, soy, legumes, beverages, and broths). To determine the primary food-based sources of PUFAs within each food group, the percent of PUFAs consumed from each ingredient within a food group was computed. 
Table 1. Food group constituents and sources of PUFAs within food groups in youth with type 1 diabetes in the SEARCH Nutrition Ancillary Study sample.

\begin{tabular}{|c|c|c|c|}
\hline Food Group & Constituents of Food Group & $\begin{array}{l}\% \text { PUFA Intakes from } \\
\text { Food Group }\end{array}$ & $\begin{array}{l}\text { Primary Sources of PUFAs in Food } \\
\text { Group (\% PUFAs in Food Group) }\end{array}$ \\
\hline Nonsolid Fats & $\begin{array}{l}\text { salad dressings, canola oil, corn } \\
\text { oil, cottonseed oil, olive oil, } \\
\text { soybean oil, vegetable oil }\end{array}$ & 28.1 & $\begin{array}{c}\text { Soybean oil }(35.9 \%) \text {, Ranch salad } \\
\text { dressing regular }(24.8 \%) \text {, unknown oil } \\
(20.3 \%) \text {, mayonnaise or mayo type } \\
\text { dressing }(10.1 \%)\end{array}$ \\
\hline Nuts & $\begin{array}{l}\text { almonds, cashews, peanut butter, } \\
\text { peanuts, walnuts }\end{array}$ & 13.5 & $\begin{array}{l}\text { Roasted peanuts }(54.7 \%) \text {, peanut butter } \\
(31.4 \%) \text {, walnuts }(9.7 \%)\end{array}$ \\
\hline Grains & $\begin{array}{l}\text { bagel, biscuit, bread, cornbread, } \\
\text { taco shell, tortilla, buns, cereal, egg } \\
\text { rolls, starch, French toast, grits, } \\
\text { hush puppies, cornstarch, flour, } \\
\text { pancakes, pita, waffles, granola, } \\
\text { oatmeal, pasta, noodles, rice }\end{array}$ & 11.3 & $\begin{array}{l}\text { White bread }(15.7 \%) \text {, wheat bread } \\
(10.5 \%) \text {, pancakes }(10.3 \%) \text {, flour } \\
\text { tortilla }(7.4 \%)\end{array}$ \\
\hline $\begin{array}{l}\text { Red and Processed } \\
\text { Meats }\end{array}$ & $\begin{array}{l}\text { beef, hamburger, chili, pork, } \\
\text { venison, bacon, bologna, corn dog, } \\
\text { ham, hot dogs, lunch meats, } \\
\text { sausage }\end{array}$ & 8.9 & $\begin{array}{c}\text { Pork sausage }(22.0 \%), \text { hamburger } \\
(10.7 \%), \text { pork ribs }(9.6 \%), \text { bologna } \\
(7.1 \%) \text {, bacon }(7.0 \%), \text { hot dogs }(7.0 \%), \\
\text { Vienna sausage }(6.6 \%)\end{array}$ \\
\hline High-fat Chicken & $\begin{array}{l}\text { chicken nuggets (fast food), } \\
\text { chicken with skin }\end{array}$ & 7.5 & $\begin{array}{l}\text { Fast food chicken nuggets }(69.6 \%) \text {, } \\
\text { chicken (light or dark) with skin } \\
(19.4 \%) \text {, chicken (light or dark) with } \\
\text { skin removed }(6.9 \%)\end{array}$ \\
\hline Low-fat Chicken & $\begin{array}{l}\text { Chicken, breast, skin removed } \\
\text { before cooking }\end{array}$ & 0.3 & $\begin{array}{c}\text { Chicken, breast, skin removed before } \\
\text { cooking }(100 \%)\end{array}$ \\
\hline $\begin{array}{l}\text { Sweets and } \\
\text { Desserts }\end{array}$ & $\begin{array}{l}\text { fruit roll ups, cinnamon buns, } \\
\text { cakes, candy, cookies, doughnuts, } \\
\text { high fructose corn syrup, honey, } \\
\text { ice cream, jelly, pies, pudding, } \\
\text { sugar, syrups, turnovers }\end{array}$ & 7.7 & $\begin{array}{c}\text { Cake }(28.3 \%), \text { cookies }(26.9 \%), \\
\text { doughnuts }(21.3 \%), \text { ice cream and } \\
\text { frozen desserts }(5.7 \%)\end{array}$ \\
\hline Chips and Crackers & $\begin{array}{l}\text { corn chips, potato chips, snack } \\
\text { crackers, popcorn, pretzels }\end{array}$ & 5.9 & $\begin{array}{c}\text { Snack crackers }(45.0 \%) \text {, potato chips } \\
(24.0 \%) \text {, corn chips }(19.1 \%), \\
\text { peanut-butter filled sandwich }(5.1 \%)\end{array}$ \\
\hline Solid Fats & $\begin{array}{l}\text { butter, shortening, animal fats, } \\
\text { margarine, animal gravy, lard }\end{array}$ & 3.3 & $\begin{array}{c}\text { Margarine }(70.0 \%) \text {, vegetable } \\
\text { shortening }(15.7 \%) \text {, poultry gravy } \\
(5.9 \%) \text {, pork fat }(5.9 \%)\end{array}$ \\
\hline Dairy & $\begin{array}{l}\text { cheese, cottage cheese, whey, milk, } \\
\text { buttermilk, cream, yogurt }\end{array}$ & 3.2 & $\begin{array}{c}\text { Cheddar cheese }(35.4 \%), 2 \% \text { or reduced } \\
\text { fat milk }(20.4 \%) \text {, whole milk yogurt } \\
(13.5 \%) \text {, whole milk }(8.7 \%) \text {, mozzarella } \\
\text { cheese }(5.8 \%)\end{array}$ \\
\hline Vegetables & $\begin{array}{l}\text { broccoli, collards, salad, spinach, } \\
\text { turnip greens, bok choy, mustard } \\
\text { greens, parsley, spinach, Brussels } \\
\text { sprouts, cabbage, cauliflower, } \\
\text { relish, green beans, peppers, yeast, } \\
\text { okra onion, squash, celery, garlic, } \\
\text { ginger, lettuce, mushrooms, peas, } \\
\text { potatoes, carrots, corn, BBQ sauce, } \\
\text { catsup, salsa, tomato, tomato } \\
\text { sauce/paste }\end{array}$ & 2.4 & $\begin{array}{c}\text { Mashed potatoes }(41.2 \%), \text { corn }(7.2 \%), \\
\text { green peas }(5.7 \%)\end{array}$ \\
\hline Fish and Seafood & fish, seafood & 2.3 & $\begin{array}{l}\text { Tuna salad with mayo (no egg) }(54.1 \%) \text {, } \\
\text { salmon }(37.1 \%)\end{array}$ \\
\hline Eggs & eggs & 1.8 & $\begin{array}{c}\text { Cooked whole eggs ( } 52.6 \%) \text {, Ingredient } \\
\text { whole eggs }(29.8 \%) \text {, ingredient egg yolk } \\
(6.8 \%) \text {, boiled eggs }(5.5 \%)\end{array}$ \\
\hline Sports Bars & $\begin{array}{c}\text { granola bars, cereal bars, power } \\
\text { bars }\end{array}$ & 1.1 & $\begin{array}{c}\text { Cereal bars }(65.5 \%), \text { granola } \\
\text { bars }(31.9 \%)\end{array}$ \\
\hline Meal Replacements & $\begin{array}{l}\text { meal replacement products, bars } \\
\text { and drinks }\end{array}$ & 1.0 & $\begin{array}{c}\text { Breakfast bars }(74.4 \%) \text {, energy snack } \\
\text { bars }(14.0 \%), \text { low calorie meal } \\
\text { replacement drink }(11.6 \%)\end{array}$ \\
\hline Fruit & $\begin{array}{c}\text { apricot, bananas, figs, grapes, } \\
\text { mango, plantains, prune, raisins, } \\
\text { orange, tangerine, apple, } \\
\text { applesauce, berries, cantaloupe, } \\
\text { fruit cocktail, melon, papaya, } \\
\text { peach, pear, persimmon, fruit } \\
\text { juices, vinegar }\end{array}$ & 0.9 & $\begin{array}{c}\text { Plantains }(32.9 \%) \text {, banana }(10.8 \%), \\
\text { orange juice }(10.7 \%) \text {, apple }(8.4 \%) \text {, apple } \\
\text { cider }(7.4 \%)\end{array}$ \\
\hline Soy & $\begin{array}{l}\text { soy protein concentrate, soy milk, } \\
\text { soy sauce, Worcestershire sauce, } \\
\text { tofu, soybeans }\end{array}$ & 0.5 & Cooked tofu $(78.4 \%)$, soy milk ( $18.3 \%)$ \\
\hline Legumes & $\begin{array}{l}\text { baked beans, refried beans, kidney } \\
\text { beans, garbanzo beans }\end{array}$ & 0.2 & $\begin{array}{c}\text { Refried beans }(68.4 \%) \text {, baked } \\
\text { beans }(22.0 \%)\end{array}$ \\
\hline
\end{tabular}

PUFA, Polyunsaturated fatty acid; ${ }^{1}$ Foods indicate components of food group contributing $5 \%$ or more to the total PUFAs in the food group. Foods in bold contribute more than $5 \%$ of PUFAs overall (across all food groups). For example, soybean oil contributed to $10.1 \%$ of total PUFAs; roasted peanuts, $7.4 \%$; ranch style dressing, $7.0 \%$; unknown oil, $5.7 \%$; chicken nuggets, $5.5 \%$. 


\subsection{Lipid Levels}

Lipid levels were assessed by the Northwest Lipid Metabolism and Diabetes Research Laboratories in Seattle, Washington from plasma samples processed at the site and shipped within $24 \mathrm{~h}$. A Hitachi 917 autoanalyzer (Boehringer Mannheim Diagnostics, Indianapolis, IN) was used for assays of plasma cholesterol, triglyceride, and HDL cholesterol. The Friedewald equation was used to calculate LDL cholesterol if triglyceride concentration was $<400 \mathrm{mg} / \mathrm{dL}(4.52 \mathrm{mM} / \mathrm{L})$ and by the Beta Quantification procedure if triglyceride was $\geq 400 \mathrm{mg} / \mathrm{dL}$ [16].

\subsection{Other Variables}

Medical record abstraction was used to abstract information on clinical presentation and care. Age, gender, race, ethnicity, and date of diagnosis of diabetes were all captured by self-report. Standard census categories were used to capture race and ethnicity [17].

\subsection{Statistical Analysis}

The SNAS study was powered based on the primary aim of examining the relationship between nutrients (including PUFAs) and subclinical cardiovascular disease. For type 1 diabetes, there was over $80 \%$ power to detect a difference of 0.1 standard deviation (SD) in the continuous outcome of interest (e.g., pulse wave velocity) with a change of 1 SD in the dietary exposure. This was a secondary analysis of the SNAS study was expected have comparable power to the primary aim based on use of the same analytic method (regression of a continuous variable on nutrients of interest). Participant characteristics and intakes of PUFAs from specific food groups were summarized using descriptive statistics.

LDL cholesterol was transformed for modelling using the natural log due to skewness. Results were back-transformed to the original scale for interpretation. We fit a linear model with total PUFA intake as the predictor variable and LDL as the outcome, controlling for non-PUFA fats, protein, and carbohydrates, as well as age, race, gender, and duration of diabetes. The inclusion of all macronutrients in the model effectively adjusts for non-PUFA energy intake. Next, a model was fit including each of the different food group-based sources of total PUFA intakes (rather than their sum as in the first model) with the same covariates. This model allowed for the estimation of the relationship between PUFAs sourced from each food group with LDL. Substitution effects, i.e., the effects on LDL of trading PUFAs from one food group for another, were estimated using linear contrasts. Because the model controls for all non-PUFA macronutrients, we restrict the substitution to food group-based sources of PUFAs rather than for other macronutrients. Similar models were fit separately for $n-3$ PUFAs and n-6 PUFAs. Beta coefficients were reported for a 10-kcal change in the food group based PUFA to aid interpretation. All analyses were performed in SAS (v 9.4, Cary, NC), at a two-sided alpha level of 0.05 .

\section{Results}

Of the 1861 participants with type 1 diabetes whose diabetes was prevalent in 2001 or incident in 2002-2005 who were $\geq 10$ years of age at the time of their baseline study visit, 89 were excluded because they had diabetes for less than three months at the time of their study visit, 128 were missing the FFQ, 188 were excluded for missing fasting lipids, 15 were excluded for reporting energy values below $2092 \mathrm{~kJ}$ (500 kcal) or above $20920 \mathrm{~kJ}$ (5000 kcal), and six were excluded for taking lipid lowering medications, for a final analytic sample of 1435 .

The participants were 14 years old on average, 51\% female, and had a diagnosis of type 1 diabetes for 3.6 years, with an average energy consumption ranging from $6653 \mathrm{~kJ} /$ day (1590 kcal/day) to 8452 $\mathrm{kJ} /$ day (2020 kcal/day) characterized by age and gender, with $48 \%$ of energy from carbohydrates and $16 \%$ of energy from protein (Table 2). The mean intake of PUFAs derived from the FFQ was 14.9 g/day, or $562 \mathrm{~kJ} /$ day (134.4 kcal/day, 7.6\% of energy), with the highest intake sources of PUFAs from nonsolid fats, nuts, grains, red and processed meats, sweets and desserts, and chicken (Table 1,Table 3). 
The primary sources of PUFAs by food group are presented in Table 1 (e.g., soybean oil comprised $35.9 \%$ of PUFA consumption in the nonsolid fats category). However, some food groups contributed very little to overall PUFA intake. Across all food groups, the highest food sources were soybean oil, regular ranch salad dressing, roasted peanuts, oil of unknown type, and fast food chicken nuggets.

Table 2. Descriptive characteristics of youth with type 1 diabetes in SEARCH Nutrition Ancillary Study sample.

\begin{tabular}{|c|c|c|}
\hline Characteristics & \multicolumn{2}{|c|}{$(n=1435)$} \\
\hline & $n$ & $\%$ \\
\hline \multicolumn{3}{|c|}{ Gender } \\
\hline Female & 730 & 50.9 \\
\hline Male & 705 & 49.1 \\
\hline \multicolumn{3}{|l|}{ Race } \\
\hline White & 1147 & 79.9 \\
\hline Black & 103 & 7.2 \\
\hline \multirow[t]{2}{*}{ Other } & 185 & 12.9 \\
\hline & Mean & SD \\
\hline Age (years) & 14.5 & 2.9 \\
\hline Duration of diabetes (months) & 43.4 & 42.7 \\
\hline non-PUFA fats, kcal/day & 508.4 & 241.1 \\
\hline Protein, kcal/day & 279.7 & 121.2 \\
\hline Carbohydrates, kcal/day & 839.1 & 356.9 \\
\hline Fiber, g/1000 kcal & 7.9 & 2.4 \\
\hline \multicolumn{3}{|c|}{ Energy, kcal/day } \\
\hline Female, $10-13$ years & 1613 & 666 \\
\hline Male, 10-13 years & 1824 & 682 \\
\hline Female, $14-22$ years & 1590 & 633 \\
\hline Male, $14-22$ years & 2020 & 807 \\
\hline
\end{tabular}

The relationship of $\log$ LDL cholesterol on $n-3$ and $n-6$ PUFAs from all food sources summed together was first examined. A significant relationship was not found $(b=-0.0004, p=0.85$ for a 41.8-kJ (10-kcal) difference). Next, a model including PUFAs from the different food group-based sources was fit. In this model, PUFAs from nuts were inversely associated with the natural log of LDL cholesterol $(b=-0.0075, p=0.03$ for a 41.8-kJ (10-kcal) difference) and PUFAs from high-fat chicken $(b=0.0182, p<0.01$ for a $41-8 \mathrm{~kJ}(10-\mathrm{kcal})$ difference) and grains $(b=0.0197, p=0.05$ for a 41.8-kJ (10-kcal) difference) were positively associated with LDL cholesterol; PUFAs from sweets and desserts, dairy, red and processed meats, eggs, nonsolid fats, solid fats, chips and crackers, fish and seafood, vegetables, and other sources were not significantly associated with log LDL cholesterol (Table 4) in adjusted models. As illustrated in Figure 1, slopes of the relationship between different food group-based sources of PUFAs and LDL cholesterol from this model were quite variable with some food group-based sources of PUFAs exhibiting positive relationships with LDL cholesterol (high-fat chicken, grains, fish/seafood, vegetables, solid fats, and eggs), and others exhibiting null relationships (dairy, red/processed meats, sweets and desserts, nuts, nonsolid fats, chips and crackers, and other sources of PUFAs). Most of these relationships were not statistically significant, indicating that the slopes were not statistically different from zero.

Substituting $30 \mathrm{kcal} /$ day of PUFA intake from nuts for PUFA intake from high-fat chicken was associated with a decrease in LDL cholesterol of $7.4 \mathrm{mg} / \mathrm{dL}$ (95\% CI: 3.4, $11.3 \mathrm{mg} / \mathrm{dL}$, Figure 1). As indicated by the vertical dashed line in the figure, a $126 \mathrm{~kJ} / \mathrm{d}$ (30 kcal/day) intake was associated with an average LDL cholesterol of $99.2 \mathrm{mg} / \mathrm{dL}$ (95\% CI: 89.0, $109.5 \mathrm{mg} / \mathrm{dL}$ ) when consumed from chicken, but $91.9 \mathrm{mg} / \mathrm{dL}(95 \% \mathrm{CI}: 82.4,101.4 \mathrm{mg} / \mathrm{dL})$ from nuts. In addition, other fat intake was positively associated with $\log \operatorname{LDL}(p=0.01)$, and protein intake was negatively associated with log 
LDL $(p<0.01)$. High-fat chicken was also significantly associated with increased $\log$ LDL for $n-3$ PUFAs and $n-6$ PUFAs, and nuts were associated with decreased log LDL for $n-6$ PUFAs, when examined separately (Table S1). In the analysis of $n-3$ PUFAs, grains were positively correlated with log LDL cholesterol, and $n$-3 PUFAs from nuts were no longer statistically significant ( $p=0.08$ ) (Table S1). Notably, grains had a $p$-value $<0.10$ for the $n$-6 PUFA model (Table S1).

Table 3. PUFA nutrient intakes (kcal/day) by food group in youth with type 1 diabetes in the SEARCH Nutrition Ancillary Study sample $(n=1435)$.

\begin{tabular}{ccccccc}
\hline & \multicolumn{2}{c}{$n$-3 and $n$-6 } & \multicolumn{2}{c}{$n$-3 PUFAs } & \multicolumn{2}{c}{$n$-6 PUFAs } \\
\cline { 2 - 7 } & Mean & SD & Mean & SD & Mean & SD \\
\hline Nonsolid Fats & 38.0 & 24.9 & 4.3 & 2.8 & 33.8 & 22.1 \\
Nuts & 18.3 & 33.3 & 0.4 & 0.9 & 18.0 & 32.5 \\
Grains & 15.3 & 9.7 & 1.3 & 0.8 & 14.0 & 8.8 \\
Red and Processed Meats & 11.7 & 9.2 & 1.0 & 0.8 & 10.7 & 8.5 \\
Sweets and Desserts & 10.5 & 13.9 & 1.1 & 1.4 & 9.4 & 12.6 \\
High-fat Chicken & 10.0 & 12.9 & 1.0 & 1.3 & 9.0 & 11.6 \\
Chips and Crackers & 8.0 & 7.8 & 0.5 & 0.6 & 7.5 & 7.3 \\
Solid Fats & 4.5 & 4.2 & 0.4 & 0.4 & 4.1 & 3.8 \\
Dairy & 4.2 & 2.8 & 1.2 & 1.0 & 3.0 & 1.9 \\
Vegetables & 3.2 & 2.9 & 0.6 & 0.6 & 2.6 & 2.5 \\
Fish and Seafood & 3.0 & 6.2 & 0.8 & 1.7 & 2.1 & 4.5 \\
Eggs & 2.5 & 2.6 & 0.1 & 0.2 & 2.3 & 2.4 \\
Sports Bars & 1.5 & 2.7 & 0.1 & 0.2 & 1.4 & 2.5 \\
Meal Replacements & 1.3 & 2.2 & 0.2 & 0.3 & 1.2 & 1.9 \\
Fruit & 1.2 & 1.2 & 0.3 & 0.2 & 1.0 & 1.0 \\
Soy & 0.6 & 2.2 & 0.1 & 0.3 & 0.5 & 1.9 \\
Low-fat Chicken & 0.4 & 0.7 & $<0.1$ & 0.1 & 0.4 & 0.7 \\
Legumes & 0.2 & 0.5 & 0.1 & 0.2 & 0.1 & 0.3 \\
Beverages and Broths & $<0.1$ & 0.1 & 0.0 & 0.0 & $<0.1$ & 0.1 \\
Other ${ }^{1}$ & 5.3 & 5.6 & 0.7 & 0.7 & 4.6 & 5.0 \\
Total & 134.4 & 67.6 & 13.5 & 6.5 & 121.0 & 61.8 \\
\hline
\end{tabular}

PUFA, Polyunsaturated fatty acid; ${ }^{1}$ Sum of food groups with total PUFA intakes $<2.5 \mathrm{kcal} /$ day.

Table 4. Model ${ }^{1}$ of $n$-3 plus $n$-6 PUFA food group-based intakes on log LDL cholesterol in youth with type 1 diabetes in the SEARCH Nutrition Ancillary Study sample $(n=1435)$.

\begin{tabular}{cccc}
\hline Parameter & Estimate $^{2}$ & SE & $p$-Value \\
\hline Intercept & 4.5418 & 0.0495 & $<0.0001$ \\
PUFA intakes from food group ${ }^{3}:$ & \\
Sweets/ Desserts & -0.0120 & 0.0080 & 0.1342 \\
Grains & 0.0197 & 0.0100 & 0.0495 \\
Dairy & -0.0296 & 0.0415 & 0.4763 \\
Nuts & -0.0075 & 0.0034 & 0.0293 \\
Red/Processed meat & -0.0185 & 0.0158 & 0.2400 \\
Eggs & 0.0098 & 0.0308 & 0.7506 \\
Nonsolid fats & -0.0038 & 0.0037 & 0.3069 \\
Fats & 0.0028 & 0.0198 & 0.8883 \\
Chips/Crackers & -0.0050 & 0.0099 & 0.6156 \\
Fish/Seafood & 0.0133 & 0.0126 & 0.2913 \\
High-fat Chicken & 0.0182 & 0.0065 & 0.0053 \\
Vegetables & 0.0211 & 0.0301 & 0.4829 \\
Other & -0.0016 & 0.0146 & 0.9127 \\
Fats, non-PUFA & 0.0042 & 0.0017 & 0.0111 \\
Protein & -0.0078 & 0.0024 & 0.0014 \\
Carbohydrates & 0.0002 & 0.0004 & 0.5845 \\
Total Fiber (g/1000 kcal) & -0.0031 & 0.0038 & 0.4134 \\
\hline
\end{tabular}

${ }^{1}$ Adjusted for age, race, gender, and duration of diabetes. Model includes all variables listed in table and covariates. All variables are modeled as kcal except for fiber (g/1000 kcal); ${ }^{2}$ Estimate is for a $10 \mathrm{kcal}(41.8 \mathrm{~kJ})$ change (except for fiber); ${ }^{3}$ See Table 1 for a definition of food groups and primary sources of PUFAs. 


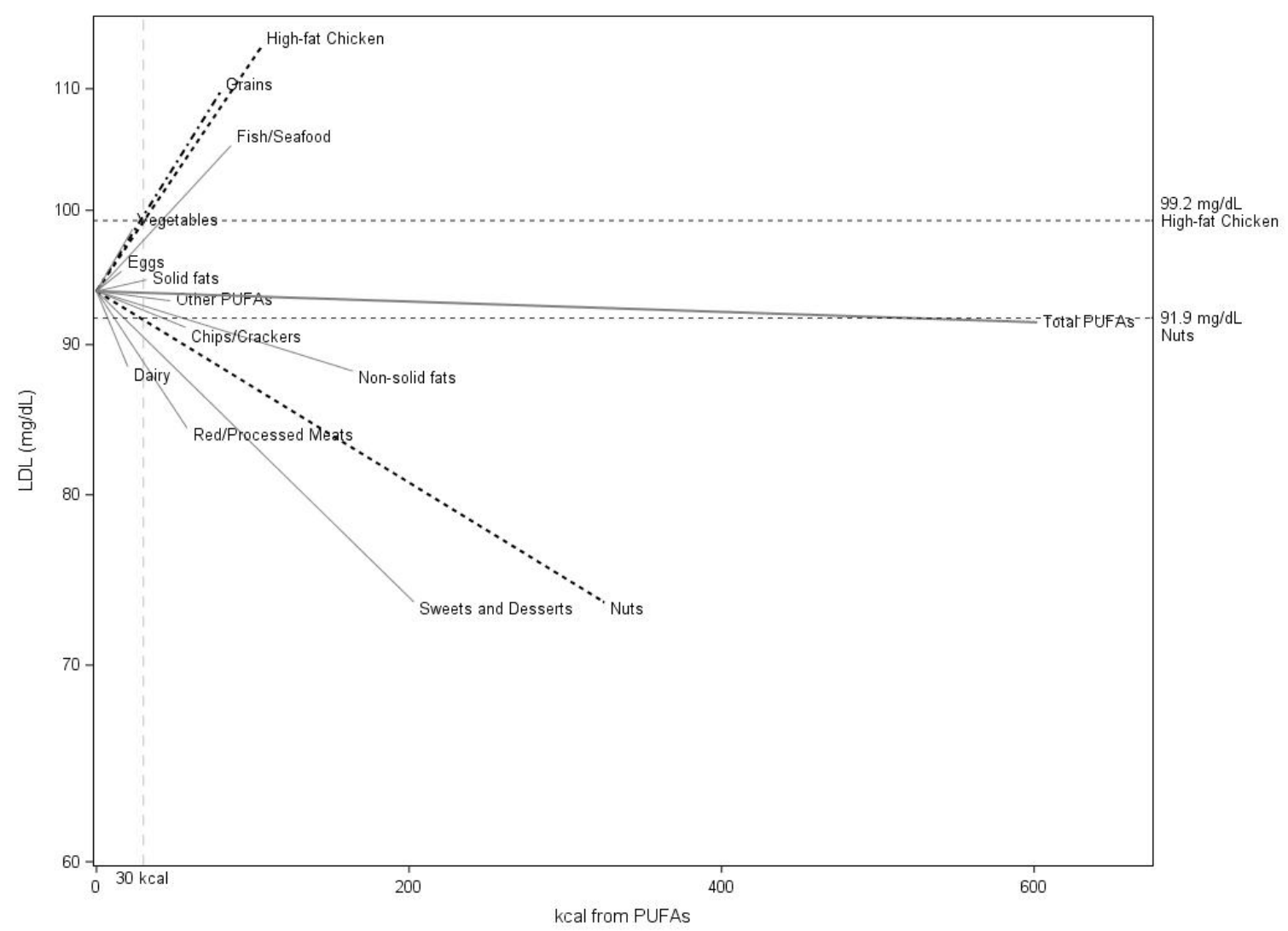

Figure 1. Relationship of kcal from n-3 and n-6 PUFAs by food group-based source and total PUFAs on LDL cholesterol in youth with type 1 diabetes in the in the SEARCH Nutrition Ancillary Study sample based on the model for combined food groups (Total PUFAs) and the model presented in Table 4 fit by food group, with both models adjusted for other fats, protein, carbohydrates, fiber, age, race, gender, and duration of diabetes, with back-transformation to the original scale for LDL cholesterol. The dashed black lines represent significant relationships for $n-3$ plus $n-6$ PUFAs from nuts, grains, and high-fat chicken. The length of the line represents the maximum kcal PUFA intake in the population. Solid gray lines depict other nonsignificant relationships. The dashed vertical line indicates $30 \mathrm{kcal} /$ day ( $126 \mathrm{~kJ} /$ day) of $n-3$ plus $n-6$ PUFA intake, and the horizontal dashed lines indicate predicted LDL cholesterol values on the vertical axis for $30 \mathrm{kcal}(126 \mathrm{~kJ} /$ day) intake of PUFAs from nuts or from chicken. See Table 1 for a definition of the food groups and predominant sources of PUFAs.

\section{Discussion}

In a sample of youth with type 1 diabetes, we examined the relationship between food group-based PUFA sources and LDL cholesterol levels. The results suggest that substituting PUFAs from nuts for PUFAs from high-fat chicken would be associated with a significant decrease in LDL cholesterol. We also found that PUFA intake from grains was positively associated with LDL cholesterol.

In a pooled analysis of 25 nut intervention studies, an average consumption of $67 \mathrm{~g}$ of nuts per day was associated with a $10.2 \mathrm{mg} / \mathrm{dL}$ reduction in LDL [18], consistent with our analysis. A difference in the specific PUFAs and the ratios of PUFAs contained within the food groups or of other constituents of these food groups could explain differences in action of nuts compared to high-fat chicken. Nuts are high in dietary fat, ranging from $46 \%-76 \%$ with the exception of chestnuts, and many of them contain high levels of both PUFAs and MUFAs. Most nuts have more MUFAs than PUFAs, but the ratio varies by type of nut. For this particular FFQ, roasted peanuts were assumed to be the primary source of nuts, and fast food chicken nuggets were the primary source of high-fat chicken. Roasted peanuts consist of $49.7 \%$ fat by weight, with almost half of the fat (24.6\%) from MUFA (predominantly 18:1) and almost one-third (15.7\%) from PUFA, which is primarily 18:2 n-6 (linoleic acid) [19], and only 
0.003\% n-3 PUFAs. Chicken nuggets contain 18.4\% fat by weight, with over one-third (6.8\%) from monounsaturated fatty acids (MUFA, predominately 18:1), and close to one-third (6.5\%) from PUFA, with the majority (7.2\%) from 18:2, as well as 0.9\% from 18:3 (gamma-linoleic acid) and 0.03\% from 20:4 PUFAs (arachidonic acid) [19]. Both food sources predominately contained 18:2 PUFAs, suggesting it was not the type of PUFA that impacted the action.

We found only one study that had examined the relationship between grain intake and LDL cholesterol in youth with type 1 diabetes [20]. The authors identified that an increase in whole grain intake was associated with a significant decrease in LDL cholesterol, and that an increase in refined grains was associated with an increase in LDL cholesterol, although the latter did not reach statistical significance $(p=0.10)$. The cross-sectional pattern was similar, although the coefficients did not achieve statistical significance ( $p$-values for both whole grains and refined grains were 0.08 ). As seen in Table 1 , the primary PUFA sources in the grains group were from refined grain sources and are consistent with the previous study.

Although other authors have examined food and food group-specific nutrient substitution effects presented [6-8], this approach is not commonly used. We illustrated how the method could be used to examine the relationship between PUFAs and LDL cholesterol with careful control for other macronutrients and fiber and found differences by food group-based PUFAs that were not apparent when examining total PUFAs. A possible explanation is that aggregating the effects of PUFAs masks the effects of different food group-based sources of PUFAs. Additionally, when interpreting food group-based nutrient analyses, the food group often includes both the nutrients from the food itself (e.g., PUFAs found in chicken), as well as from preparation methods of the food (e.g., added fat). Therefore, it is important to examine the highest sources of the nutrient in a food group when drawing conclusions about food group-based effects and disseminating results.

Because foods are complex, there are multiple components that have independent and synergistic effects on health [21]. Rather than trying to isolate all these components individually, we chose to examine a plausible nutrient pathway, specifically the relationship between PUFA and LDL cholesterol, and then to examine which foods might contribute most strongly to the association between that nutrient and LDL cholesterol. It is possible that other components of the foods consumed may have beneficial or negative effects on LDL cholesterol. For example, peanuts contain higher levels of potassium, magnesium, copper, and phosphorous than chicken nuggets, and are sources of tocopherols and phenolic antioxidants that impact LDL oxidation $[19,22]$.

One advantage of the approach used in this manuscript is that it allowed for specific dietary guidance with regards to a health outcome, e.g., substituting nuts for high-fat chicken intake lowered LDL cholesterol and held energy and total fiber intake constant in the process. It also allowed us to examine the common sources of PUFAs in this particular population of youth with diabetes to inform recommendations. Therefore, we anticipate that this approach may be useful to simultaneously examine the effects of nutrients, which offer a mechanism for the effect, and food groups, which are easily amenable to dietary guidance.

This study does have some limitations. Notably, we relied on an FFQ to estimate dietary intake. Due to its questionnaire format, several assumptions have to be made regarding recipe content and ingredients. For example, one of the FFQ line items associated with nuts were "peanuts or other nuts or seeds?", which was assumed to primarily comprise peanuts and peanut butter, but a child's diet may include only tree nuts or seeds and no peanuts and these differences would not be captured by the FFQ. Similarly, fast food chicken nuggets were assumed to be the most commonly consumed food for the line item "fried chicken, including chicken nuggets, chicken sandwich, or chicken wings?", but preparation methods of fried chicken may vary widely, and nutrient quality can be affected by cooking methods. For example, frying is associated with oxidation of oils and its nutritional properties [23], and nutritional content of both chicken nuggets and peanuts has been shown to vary by cooking method [24,25]. It was also not possible to examine multiple types of food group-based sources of nutrients in the same model (e.g., saturated fat and PUFAs from nuts) due to collinearity. The use 
of a $24 \mathrm{~h}$ recall might mitigate some of these issues. Furthermore, FFQs are prone to systematic and random sources of measurement error, which may have impacted the validity of our results. However, the FFQ used in this study was developed for children as young as eight years old, and many parents assisted children under the age of 12 with completion. A validation study of this FFQ found moderate correlations for total fat ( $r=0.40$ unadjusted, 0.48 measurement error adjusted) and linoleic acid ( $r=$ 0.26 unadjusted, $r=0.37$ adjusted) on the FFQ compared to $24 \mathrm{~h}$ recalls [16]. Furthermore, we were limited by the cross-sectional nature of the analysis.

\section{Conclusions}

Due to the complexities of diet and dietary patterns, evaluating the relationship between a nutrient and a health outcome may benefit from examining food group-based sources of nutrients, which requires quantifying nutrients within food groups from a dietary assessment tool. Relationships identified in this manner could be further tested in clinical trials or feeding study to inform dietary guidance. In particular, this analysis supports further study of the substitution of nuts for high-fat chicken intake and refined grains in youth with type 1 diabetes to lower LDL cholesterol.

Supplementary Materials: The following are available online at http://www.mdpi.com/2072-6643/12/4/941/s1, Table S1: Models ${ }^{*}$ of stratified n-3 and n-6 PUFA food group-based intakes on log LDL cholesterol in youth with type 1 diabetes in the SEARCH Nutrition Ancillary Study sample.

Author Contributions: J.A.T., N.S.T., J.L.C., and A.D.L. developed the research question for this analysis; E.J.M.-D., N.S.T., J.L.C., A.D.L., and S.C.C. designed the SEARCH Nutrition Ancillary Study and carried it out; J.A.T. and J.L.C. were responsible for analyzing the data; J.A.T. drafted the manuscript and all authors contributed to writing and editing the manuscript and approved the final draft. All authors have read and agreed to the published version of the manuscript.

Funding: The SEARCH Nutrition Ancillary study was funded by the National Institutes of Health, National Institute of Diabetes and Digestive and Kidney Diseases (R01DK077949) and The SEARCH for Diabetes in Youth Study has been funded by the Centers for Disease Control and Prevention (awards U48/CCU919219, U01DP000246, U18DP002714, and U18DP006133) with support from the National Institutes of Diabetes and Digestive and Kidney Diseases (provided funding for publication).

Conflicts of Interest: The authors declare no conflict of interest.

\section{References}

1. Baum, S.J.; Kris-Etherton, P.M.; Willett, W.C.; Lichtenstein, A.H.; Rudel, L.L.; Maki, K.C.; Whelan, J.; Ramsden, C.E.; Block, R.C. Fatty acids in cardiovascular health and disease: A comprehensive update. J. Clin. Lipid 2012, 6, 216-234. [CrossRef]

2. Czernichow, S.; Thomas, D.; Bruckert, E. N-6 fatty acids and cardiovascular health: A review of the evidence for dietary intake recommendations. Br. J. Nutr. 2010, 104, 788-796. [CrossRef]

3. Clifton, P.M.; Keogh, J.B. A systematic review of the effect of dietary saturated and polyunsaturated fat on heart disease. Nutr. Metab. Cardiovasc. Dis. 2017, 27, 1060-1080. [CrossRef]

4. Schwab, U.; Lauritzen, L.; Tholstrup, T.; Haldorssoni, T.; Riserus, U.; Uusitupa, M.; Becker, W. Effect of the amount and type of dietary fat on cardiometabolic risk factors and risk of developing type 2 diabetes, cardiovascular diseases, and cancer: A systematic review. Food Nutr. Res. 2014, 58. [CrossRef]

5. Kipnis, V.; Freedman, L.S.; Brown, C.C.; Hartman, A.; Schatzkin, A.; Wacholder, S. Interpretation of energy adjustment models for nutritional epidemiology. Am. J. Epidemiol. 1993, 137, 1376-1380. [CrossRef]

6. De Oliveira Otto, M.C.; Mozaffarian, D.; Kromhout, D.; Bertoni, A.G.; Sibley, C.T.; Jacobs, D.R., Jr.; Nettleton, J.A. Dietary intake of saturated fat by food source and incident cardiovascular disease: The Multi-Ethnic Study of Atherosclerosis. Am. J. Clin. Nutr. 2012, 96, 397-404. [CrossRef]

7. Praagman, J.; Beulens, J.W.; Alssema, M.; Zock, P.L.; Wanders, A.J.; Sluijs, I.; van der Schouw, Y.T. The association between dietary saturated fatty acids and ischemic heart disease depends on the type and source of fatty acid in the European Prospective Investigation into Cancer and Nutrition-Netherlands cohort. Am. J. Clin. Nutr. 2016, 103, 356-365. [CrossRef]

8. Kulldorff, M.; Sinha, R.; Chow, W.H.; Rothman, N. Comparing odds ratios for nested subsets of dietary components. Int. J. Epidemiol. 2000, 29, 1060-1064. [CrossRef] [PubMed] 
9. Wiltshire, E.J.; Hirte, C.; Couper, J.J. Dietary fats do not contribute to hyperlipidemia in children and adolescents with type 1 diabetes. Diabetes Care 2003, 26, 1356-1361. [CrossRef] [PubMed]

10. Saito, M.; Kuratsune, H.; Nitta, H.; Kawahara, K.; Hamano, M.; Matsuda, M.; Kaku, K.; Eto, M. Plasma lipid levels and nutritional intake in childhood- and adolescence-onset young type 1 patients in Japan. Diabetes Res. Clin. Pract. 2006, 73, 29-34. [CrossRef] [PubMed]

11. Couch, S.C.; Crandell, J.L.; Peairs, A.; Liese, A.D.; Shah, A.S.; Dolan, L.M.; Tooze, J.; Crume, J.; King, I.; Mayer-Davis, E.J. Associations between long chain polyunsaturated fatty acids and cardiovascular risk factors in youth with type 1 diabetes (T1D): SEARCH Nutrition Ancillary Study. J. Diabetes Complicat. 2017, 31, 67-73. [CrossRef] [PubMed]

12. SEARCH Study Group. SEARCH for Diabetes in Youth: A multicenter study of the prevalence, incidence and classification of diabetes mellitus in youth. Control. Clin. Trials 2004, 25, 458-471. [CrossRef] [PubMed]

13. Hamman, R.F.; Bell, R.A.; Dabelea, D.; D'Agostino, R.B., Jr.; Dolan, L.; Imperatore, G.; Lawrence, J.M.; Linder, B.; Marcovina, S.M.; Mayer-Davis, E.J.; et al. The SEARCH for Diabetes in Youth study: Rationale, findings, and future directions. Diabetes Care 2014, 37, 3336-3344. [CrossRef] [PubMed]

14. Mayer-Davis, E.J.; Nichols, M.; Liese, A.D.; Bell, R.A.; Dabelea, D.M.; Johansen, J.M.; Pihoker, C.; Rodriguez, B.L.; Thomas, J.; Williams, D.; SEARCH for Diabetes in Youth Study Group. Dietary intake among youth with diabetes: The SEARCH for Diabetes in Youth Study. J. Am. Diet. Assoc. 2006, 106, 689-697. [CrossRef] [PubMed]

15. Liese, A.D.; Crandell, J.L.; Tooze, J.A.; Fangman, M.T.; Couch, S.C.; Merchant, A.T.; Bell, R.A.; Mayer-Davis, E.J Relative validity and reliability of a food frequency questionnaire in youth with type 1 diabetes. Publ. Health Nutr. 2015, 28, 1-10.

16. Hainline, A., Jr.; Miller, D.T.; Mather, A. The Coronary Drug Project. Role and methods of the central laboratory. Control. Clin. Trials 1983, 4, 377-387. [CrossRef]

17. Grieco, E.M.; Cassidy, R.C. Overview of Race and Hispanic Origin: Census 2000 Brief; US Department of Commerce, Economic and Statistics Administration, US Census Bureau: Suitland-Silver Hill, MD, USA, 2001.

18. Sabaté, J.; Oda, K.; Ros, E. Nut Consumption and Blood Lipid Levels: A Pooled Analysis of 25 Intervention Trials. Arch. Intern. Med. 2010, 170, 821-827. [CrossRef]

19. Nutrition Data System (NDS) for Research, version 4.05/33; database 3; Nutrition Coordinating Center, University of Minnesota: Minneapolis, MN, USA, 2002.

20. Sanjeevi, N.; Lipsky, L.M.; Nansel, T.R. Cardiovascular biomarkers in association with dietary intakes in a longitudinal study of youth with type 1 diabetes. Nutrients 2018, 10, 1552. [CrossRef]

21. Jacobs, D.R., Jr.; Gross, M.D.; Tapsell, L.C. Food synergy: An operational concept for understanding nutrition. Am. J. Clin. Nutr. 2009, 89, 1543S-1548S. [CrossRef]

22. Kris-Etherton, P.M.; Hu, F.B.; Ros, E.; Sabaté, J. The role of tree nuts and peanuts in the prevention of coronary heart disease: Multiple potential mechanisms. J. Nutr. 2008, 138, 1746S-1751S. [CrossRef]

23. Dobarganes, C.; Marquez-Ruiz, G. Possible adverse effects of frying with vegetable oils. Br. J. Nutr. 2015, 113 (Suppl. 2), S49-S57. [CrossRef] [PubMed]

24. Gonçalves Albuquerque, T.; Oliveira, M.B.; Sanches-Silva, A.; Cristina Bento, A.; Costa, H.S. The impact of cooking methods on the nutritional quality and safety of chicken breaded nuggets. Food. Funct. 2016, 7, 2736-2746. [CrossRef] [PubMed]

25. Juhaimi, F.A.; Ghafoor, K.; Babiker, E.E.; Özcan, M.M.; Aadiamo, O.Q.; Alsawmahi, O.N. Influence of Storage and Roasting on the Quality Properties of Kernel and Oils of Raw and Roasted Peanuts. J. Oleo. Sci. 2018, 67, 755-762. [CrossRef] [PubMed]

(C) 2020 by the authors. Licensee MDPI, Basel, Switzerland. This article is an open access article distributed under the terms and conditions of the Creative Commons Attribution (CC BY) license (http://creativecommons.org/licenses/by/4.0/). 